ORIGINAL ARTICLE

\title{
Prophylactic indomethacin for preterm infants: a systematic review and meta-analysis
}

\section{P W Fowlie, P G Davis}

See end of article for authors' affiliations

Correspondence to

Dr Davis, Royal Women's Hospital, 132 Grattan

St, Carlton, Victoria 3053,

Australia; pgd@

unimelb.edu.au

Accepted

30 December 2002
Background: Rates of long term morbidity remain unacceptably high in infants surviving after preterm birth. Prophylactic indomethacin has been shown to effectively reduce the rate of intraventricular haemorrhage in this group but there is the potential for unwanted side effects because of reduced organ perfusion.

Objective: To examine the effect of prophylactic indomethacin on mortality and short and long term morbidity of preterm infants.

Data sources: Medline (1966-2002), the Cochrane Controlled Trials Register and abstracts of the Society for Pediatric Research and the European Society for Pediatric Research were searched independently by both authors.

Review methods: Trials were included if they used a randomised design, enrolled preterm infants given intravenous indomethacin within 24 hours of birth, and reported any of the prespecified outcome measures. Each author extracted data and assessed trial quality independently, according to the methods of the Cochrane Collaboration. Data were combined in a meta-analysis where appropriate.

Results: Nineteen trials fulfilling the inclusion criteria were identified, of which four reported long term outcomes. Short term benefits of indomethacin were identified, including a reduction in the rate of severe intraventricular haemorrhage (relative risk (RR) 0.66 (95\% confidence interval (CI) 0.53 to 0.82 )) and the need for surgical ligation of a patent ductus arteriosus (RR 0.51 (95\% $\mathrm{Cl} 0.37$ to 0.71 )). No evidence of short term gastrointestinal or renal adverse effects was detected. There was no significant difference between indomethacin and control groups with respect to the important long term outcome of death or severe neurosensory impairment (RR 1.02 (95\% Cl 0.90 to 1.15$)$ ).

Conclusions: Prophylactic indomethacin has a number of short term benefits for the preterm infant but there is no evidence to suggest that it results in an improvement in the rate of survival free of disability.
T he improvement in rates of survival of very low birthweight infants is one of the more remarkable achievements in modern medicine. However, preterm birth is associated with increased risk of neurodevelopmental disability, specifically developmental delay, cerebral palsy, blindness, and deafness. The combined rates of disability range between $20 \%$ and $40 \%$ for very low birthweight infants born in the 1990s. The preterm infant is susceptible to a unique form of brain injury resulting from intraventricular haemorrhage (IVH). IVH, particularly when it involves the parenchyma of the brain, is strongly associated with poor neurodevelopmental outcome.

Indomethacin is a prostaglandin inhibitor which has long been used to treat patent ductus arteriosus (PDA) in preterm infants. More recently it has been used prophylactically in attempts to reduce the rate of IVH in high risk groups, with the aim of reducing mortality and long term morbidity.

Previous meta-analysis ${ }^{12}$ has suggested that prophylactic indomethacin leads to an improvement in short term outcomes including reduced rates of IVH, but recent publication of new studies and follow up data from previous studies allow a better evaluation of the benefits and risks of this promising treatment.

We conducted a meta-analysis using the methods and software of the Cochrane Collaboration to determine whether prophylactic indomethacin improves the outcome of preterm infants.

\section{METHODS}

\section{Search strategy}

PubMed Medline (1966-2002) was searched using the terms indomethacin and infant and (prophylactic or prophylaxis or prevention) and the Cochrane Controlled Trials Register using indomethacin and infant. Abstracts of the Society for Pediatric Research and the European Society for Paediatric Research were searched from 1996-2001, and full text articles sought using Medline searches of the authors' names. Previous reviews were cross referenced, and personal files searched for additional references. No language restrictions were applied.

\section{Inclusion criteria}

Both authors assessed all published articles and abstracts identified as potentially relevant by the literature search for inclusion in the review. In order to be included, trials had to meet all four of the following criteria:

- Study design: randomised controlled trials

- Participants: preterm infants

- Intervention: intravenous indomethacin given within 24 hours of birth

- Outcome measures: included any of the following-death, IVH, PDA, or long term neurodevelopmental outcome

\section{Quality assessment and data abstraction}

Both authors assessed each article according to the following criteria: blinding of randomisation, blinding of intervention, completeness of follow up, and blinding of outcome

Abbreviations: IVH, intraventricular haemorrhage; PDA, patent ductus arteriosus; $\mathrm{RR}$, relative risk; $\mathrm{Cl}$, confidence interval 
assessment. Both authors extracted the data from each trial independently, then compared results and resolved differences.

\section{Data analysis}

Data measuring similar outcomes were combined in a metaanalysis where appropriate. For categorical outcomes, treatment effect was analysed using relative risk (RR), risk difference, and number needed to treat with their 95\% confidence intervals (CI). A fixed effects model was used. Evaluation of heterogeneity of results was performed for all outcomes, and $p<0.05$ on $\gamma^{2}$ test was considered to represent significant heterogeneity.

\section{RESULTS}

\section{Quality assessment}

Nineteen randomised trials comprising 2872 infants fulfilled the inclusion criteria. Four of these reported long term outcomes (1862 infants). The exact method of randomisation was specified in 12 of the studies. ${ }^{3-14}$ Methods included telephone randomisation, sealed envelopes, and coded drug vials. In the remaining seven trials it was not possible to determine how well the process of randomisation was blinded. ${ }^{15-21}$ In three studies it was not possible to determine whether the caregivers and those assessing the outcomes of interest were blinded to the intervention group. ${ }^{17}{ }^{19}{ }^{20}$ In the remainder there was adequate description of methods used to ensure blinding including description of the placebo.

Follow up rates for short term outcomes were adequatethat is, $>90 \%$-for all included studies. Long term follow up rates were less complete, ranging from $75 \%$ to $100 \%$.

\section{Trial characteristics}

Table 1 shows clinical details of included studies. Some clinical practices changed over time-for example, surfactant was given either as prophylaxis or rescue therapy in seven trials. ${ }^{4}{ }^{10-14} 16$

\section{Quantitative data synthesis}

Table 2 shows the pooled results of the trials. There was no difference in mortality to latest follow up between the treatment and placebo groups (RR 0.96 (95\% CI 0.81 to 1.12)). The reduction in cranial ultrasound abnormalities (all
IVH (RR 0.88 (95\% CI 0.80 to 0.96$)$ ) and severe (grades 3 and 4) IVH (RR 0.66 (95\% CI 0.53 to 0.82$)$ ) seen in the treatment group did not translate into improved long term outcomes. Rates of mortality and severe neurosensory impairment (blindness, deafness, cerebral palsy, or developmental quotient more than two standard deviations below the mean) were high in this group of infants and were not decreased by prophylactic indomethacin (RR 1.02 (95\% CI 0.90 to 1.15)).

There were some short term advantages observed in infants given indomethacin. The rate of PDA (RR 0.44 (95\% CI 0.38 to 0.50$)$ ) and particularly the rate of surgical ligation for this condition (RR 0.51 (95\% CI 0.37 to 0.71 ) were reduced in the treatment group. Twenty infants would need to be treated with prophylactic indomethacin to prevent one surgical ligation. There were no differences in other short term outcomes including necrotising enterocolitis and bronchopulmonary dysplasia. Although oliguria was more often observed in infants receiving indomethacin, there were no differences in proportions of babies developing high serum creatinine levels.

Heterogeneity of results was found only for the outcome "all IVH" $(p=0.011)$. The remaining pooled outcomes had $p$ values $>0.2$ for heterogeneity, indicating that variability between studies may be explained by chance alone.

\section{DISCUSSION}

There is now a substantial body of literature available to evaluate the role of prophylactic indomethacin in preterm infants. The quality of trials included in this systematic review is good but there is variation in enrolment criteria, indomethacin dosage regimens, and some of the outcome definitions.

This review confirms the usefulness of prophylactic indomethacin in the prevention of symptomatic PDA. Some clinicians would find the reduction in the need for surgical ligation of the ductus, combined with the lack of evidence for short or long term harm, justification for providing this treatment. Other factors influencing such a decision would be the background rate of ligations and the availability of cardiology and cardiac surgery services.

In the past, the presence of a PDA was thought to increase the risk of developing both pulmonary haemorrhage and bronchopulmonary dysplasia. Reduction in the rate of PDA

Table 1 Clinical details of included studies

\begin{tabular}{|c|c|c|c|c|}
\hline Study (year) & $\mathbf{n}$ & Participants & Dose* & Long term follow up \\
\hline Bada (1989) & 141 & $\mathrm{BW}<1500 \mathrm{~g}$ & 3 doses starting at 6 hours & No \\
\hline Bandstra (1988) & 199 & $\mathrm{BW}<1300 \mathrm{~g}$ & 3 doses starting at $<12$ hours & Between 6 and 24 months: Bayley MDI and PDI \\
\hline Couser (1996) & 93 & BW $600-1250 \mathrm{~g}$ & 6 doses starting $<24$ hours & No \\
\hline Domenico (1994) & 100 & $\mathrm{BW}<1250 \mathrm{~g}$ & 3 doses starting $<12$ hours & No \\
\hline Gutierrez (1987) & 59 & $\begin{array}{l}\mathrm{GA}<34 \text { weeks and } \\
\mathrm{BW}<1751 \mathrm{~g}\end{array}$ & 3 doses starting $<24$ hours & No \\
\hline Hanigan (1988) & 111 & $\mathrm{BW}<1500 \mathrm{~g}$ & 3 doses starting $<12$ hours & No \\
\hline Krueger (1987) & 32 & BW $750-1500 \mathrm{~g}$ & Single dose at 24 hours & No \\
\hline Mahony (1985) & 110 & BW $700-1300 \mathrm{~g}$ & 3 doses starting at $12-18$ hours & No \\
\hline Ment (1985) & 48 & BW $600-1250 \mathrm{~g}$ & 5 doses starting at 6 hours & No \\
\hline Ment (1988) & 36 & BW $600-1250 \mathrm{~g}$ & 3 doses starting at $6-12$ hours & No \\
\hline Ment (1994a) & 61 & BW $600-1250 \mathrm{~g}$ & 3 doses starting at $6-12$ hours & No \\
\hline Ment (1994b) & 431 & BW $600-1250 \mathrm{~g}$ & 3 doses starting at $6-12$ hours & $\begin{array}{l}\text { At } 36 \text { and } 54 \text { months: Stanford Binet Intelligence } \\
\text { Scale Peabody Picture Vocabulary Test (R), CP, } \\
\text { blindness, deafness }\end{array}$ \\
\hline Morales-Suarez (1994) & 80 & GA 28-36 weeks & 3 doses starting $<12$ hours & No \\
\hline Puckett (1985) & 32 & $\mathrm{BW}<1400 \mathrm{~g}$ & 3 doses starting at $<24$ hours & No \\
\hline Rennie (1986) & 50 & $\mathrm{BW}<1750 \mathrm{~g}$ & 3 doses starting $<24$ hours & No \\
\hline Supapannachart (1999) & 30 & $\mathrm{BW}<1250 \mathrm{~g}$ & 3 doses starting $<24$ hours & No \\
\hline Schmidt (2001) & 1202 & BW $500-999 \mathrm{~g}$ & 3 doses starting $<6$ hours & $\begin{array}{l}\text { At } 18 \text { months: Bayley MDI, blindness, deafness, } \\
\mathrm{CP}\end{array}$ \\
\hline Vincer (1987) & 30 & $\mathrm{BW}<1500 \mathrm{~g}$ & 3 doses starting at 12 hours & At 24 months: $\mathrm{CP}$ \\
\hline Yaseen (1997) & 27 & $\mathrm{BW}<1750 \mathrm{lg}$ & 3 doses starting at 12 hours & No \\
\hline
\end{tabular}

*Doses were either 0.1 or $0.2 \mathrm{mg} / \mathrm{kg}$ and dosing interval 12 or 24 hours.

BW, Birth weight; GA, gestational age; MDI, mental developmental index; PDI, physical developmental index; CP, cerebral palsy. 
Table 2 Results of the trials

\begin{tabular}{|c|c|c|c|c|c|c|}
\hline Outcome & No of studies & Indomethacin & Control & Relative risk & Risk difference & NNT \\
\hline Death at latest follow up & 18 & $231 / 1372$ & $245 / 1397$ & $0.96(0.81$ to 1.12$)$ & $-0.01(-0.04$ to 0.02$)$ & \\
\hline All IVH & 14 & $422 / 1258$ & $482 / 1274$ & $0.88(0.80$ to 0.96$)$ & $-0.04(-0.08$ to -0.01$)$ & 25 \\
\hline Severe IVH & 14 & $115 / 1285$ & $177 / 1303$ & 0.66 (0.53 to 0.82$)$ & $-0.05(-0.07$ to -0.02$)$ & 20 \\
\hline Symptomatic PDA & 14 & $204 / 1093$ & $471 / 1100$ & $0.44(0.38$ to 0.50$)$ & $-0.24(-0.28$ to -0.21$)$ & 4 \\
\hline PDA ligation & 8 & $49 / 891$ & $97 / 900$ & $0.51(0.37$ to 0.71$)$ & $-0.05(-0.08$ to -0.03$)$ & 20 \\
\hline Pulmonary haemorrhage & 4 & $104 / 795$ & $123 / 796$ & 0.84 (0.66 to 1.06$)$ & $-0.02(-0.06$ to 0.01$)$ & \\
\hline BPD (in oxygen at 28 days) & 9 & $188 / 500$ & $183 / 522$ & $1.08(0.92$ to 1.26$)$ & $0.03(-0.03$ to 0.08$)$ & \\
\hline Necrotising enterocolitis & 12 & $84 / 1187$ & $77 / 1214$ & $1.09(0.82$ to 1.46$)$ & $0.01(-0.01$ to 0.03$)$ & \\
\hline Gastrointestinal perforation & 1 & $36 / 601$ & $32 / 601$ & $1.12(0.71$ to 1.79$)$ & $0.01(-0.02$ to 0.03$)$ & \\
\hline Diminished urine output & 8 & $131 / 1045$ & $70 / 1070$ & 1.90 (1.45 to 2.47$)$ & $0.06(0.04$ to 0.08$)$ & $16 \ddagger$ \\
\hline Raised creatinine & 4 & $10 / 298$ & $10 / 320$ & $1.09(0.47$ to 2.51$)$ & $0.00(-0.03$ to 0.03$)$ & \\
\hline Excessive bleeding & 5 & $16 / 880$ & $23 / 896$ & 0.74 (0.40 to 1.38$)$ & $-0.01(-0.02$ to 0.01$)$ & \\
\hline Severe developmental delay* ${ }^{*}$ & 3 & $143 / 641$ & $151 / 645$ & $0.96(0.79$ to 1.17$)$ & $-0.01(-0.05$ to 0.04$)$ & \\
\hline Cerebral palsy* & 4 & $78 / 678$ & $77 / 694$ & $1.04(0.77$ to 1.40$)$ & $0.00(-0.03$ to 0.04$)$ & \\
\hline Blindness* & 2 & $10 / 635$ & $8 / 639$ & $1.26(0.50$ to 3.18$)$ & $0.00(-0.01$ to 0.02$)$ & \\
\hline Deafness* & 2 & $11 / 626$ & $11 / 633$ & $1.02(0.45$ to 2.33$)$ & $0.00(-0.01$ to 0.01$)$ & \\
\hline $\begin{array}{l}\text { Severe neurosensory } \\
\text { impairment }^{*}\end{array}$ & 3 & $164 / 682$ & $173 / 706$ & $0.98(0.81$ to 1.18$)$ & $0.00(-0.05$ to 0.04$)$ & \\
\hline $\begin{array}{l}\text { Death or severe neurosensory } \\
\text { impairment* }\end{array}$ & 3 & $304 / 743$ & $299 / 748$ & $1.02(0.90$ to 1.15$)$ & $0.01(-0.04$ to 0.06$)$ & \\
\hline
\end{tabular}

*In survivors examined.

†Either Bayley mental developmental index (MDI <68 or Wecshler preschool and primary scale of intelligence-revised (WPPSI-R) $<70$ )

$\ddagger$ Number needed to harm.

NNT, Number needed to treat (calculated where significant result obtained); IVH, intraventricular haemorrhage; PDA, patent ductus arteriosus; BPD,

bronchopulmonary dysplasia.

without a significant change in rates of bronchopulmonary dysplasia or pulmonary haemorrhage challenges traditional assumptions about the pathophysiology of these conditions.

This review confirms the significant reduction in rates of severe intraventricular haemorrhage in infants given indomethacin. This result is not accompanied by any of the adverse outcomes that were possible given the vasoconstrictive nature of the drug - that is, important renal side effects, gastrointestinal perforation, and necrotising enterocolitis. However, the improvement in rates of IVH did not translate to improvement in rates of neurosensory impairment. One clear message of this systematic review is that traditional surrogate outcomes used in evaluating interventions in preterm infants may not be sufficient to guide changes in treatment. Put another way, when new interventions are considered in this population, particularly when they are being given prophylactically (and therefore to some infants who are not expected to benefit from them), long term outcomes should be assessed.

\section{Authors' affiliations}

P W Fowlie, Department of Child Health University of Dundee and Tayside University Hospital Trust, Dundee, Scotland, UK

P G Davis, Department of Paediatrics, Royal Women's Hospital, Melbourne and Murdoch Children's Research Institute, Melbourne, Victoria, Australia

\section{REFERENCES}

1 Fowlie P. Prophylactic indomethacin: systematic review and meta-analysis. Arch Dis Child 1996;74:F81-7.

2 Fowlie PW. Intravenous indomethacin for preventing mortality and morbidity in very low birth weight infants. Cochrane Library. Issue 2. Oxford: Update Software, 2002

3 Bandstra ES, Montalvo BM, Goldberg RN, et al. Prophylactic indomethacin for prevention of intraventricular hemorrhage in premature infants. Pediatrics 1988:82:533-42.

4 Couser RJ, Ferrara TB, Wright GB, et al. Prophylactic indomethacin therapy in the first twenty-four hours of life for the prevention of patent ductus arteriosus in preterm infants treated prophylactically with surfactant in the delivery room. J Pediatr 1996;128:631-7.
5 Gutierrez NG, Lapasset M. Prophylactic indomethacin and the incidence of patent ductus arteriosus in preterm neonates [abstract]. Proceedings of the 3rd Argentinian Congress of Perinatology 1987.

6 Hanigan WC, Kennedy G, Roemisch F, et al. Administration of indomethacin for the prevention of periventricular-intraventricular hemorrhage in high-risk neonates. J Pediatr 1988; 112:941-7.

7 Mahony L, Caldwell RL, Girod DA, et al. Indomethacin therapy on the first day of life in infants with very low birth weight. J Pediatr 1985;106:801-5.

8 Ment LR, Duncan CC, Ehrenkranz RA, et al. Randomized indomethacin trial for prevention of intraventricular hemorrhage in very low birth weight infants. J Pediatr 1985; 107:937-43.

9 Ment LR, Duncan CC, Ehrenkranz RA, et al. Randomized low-dose indomethacin trial for prevention of intraventricular hemorrhage in very low birth weight neonates. J Pediatr 1988;1 12:948-55.

10 Ment LR, Oh W, Ehrenkranz RA, et al. Low-dose indomethacin and prevention of intraventricular hemorrhage: a multicenter randomized trial. Pediatrics 1994:93:543-50.

11 Ment LR, Oh W, Ehrenkranz RA, et al. Low-dose indomethacin therapy and extension of intraventricular hemorrhage: a multicenter randomized trial. J Pediatr 1994; 124:951-5.

12 Schmidt B, Davis P, Moddemann D, et al. Long term effects of indomethacin prophylaxis in extremely-low-birth-weight infants. N Engl J Med 2001;344:1966-72

13 Supapannachart S, Khowsathit $P$, Patchakapati B. Indomethacin prophylaxis for patent ductus arteriosus (PDA) in infants with a birth weight of less than 1250 grams. J Med Assoc Thai 1999:82(suppl 1):S87-92.

14 Yaseen $\mathrm{H}$, al Umran $\mathrm{K}$, Ali $\mathrm{H}$, et al. Effects of early indomethacin administration on oxygenation and surfactant requirement in low birth weight infants. J Trop Pediatr 1997;43:42-6.

15 Bada HS, Green RS, Pourcyrous M, et al. Indomethacin reduces the risks of severe intraventricular hemorrhage. J Pediatr 1989:115:631-7.

16 Domenico RS, Waldman JD, Lester LA, et al. Prophylactic indomethacin reduce the incidence of pulmonary hemorrhage and patent ductus arteriosus in surfactant-treated infant $<1250 \mathrm{~g}$ [abstract]. Pediatr Res 1994;35:331 A.

17 Krueger E, Mellander M, Bratton D, et al. Prevention of symptomatic patent ductus arteriosus with a single dose of indomethacin. J Pediatr 1987;111:749-54.

18 Morales-Suarez M, Sanchez-Gil T, Lemus-Varela L. Estudio comparavito de dosis baja de indometicina profilactica para hemorragia subependimaria/ intraventricular en neonatos pretermino con ventilation mecanica [Low dose indomethacin for prevention of intraventricular hemorrhage in the preterm infant with mechanical ventilation: Final report of a randomized study]. Bol Med Hosp Infant Mex 1994;51:389-94.

19 Puckett CG, Cox MA, Haskins KS, et al. Prophylactic indomethacin for the prevention of patent ductus arteriosus (PDA). Pediatr Res 1985:19:358.

20 Rennie JM, Doyle J, Cooke RW. Early administration of indomethacin to preterm infants. Arch Dis Child 1986;61:233-8.

21 Vincer M, Allen A, Evans J, et al. Early intravenous indomethacin prolongs respiratory support in very low birth weight infants. Acta Paediatr Scand 1987:76:894-7. 